\title{
Ibuprofen inhibits migration and proliferation of human coronary artery smooth muscle cells by inducing a differentiated phenotype: role of peroxisome proliferator-activated receptor $y$
}

Article

Accepted Version

Dannoura, A., Giraldo, A., Pereira, I., Gibbins, J., Dash, P., Bicknell, K. and Brooks, G. (2014) Ibuprofen inhibits migration and proliferation of human coronary artery smooth muscle cells by inducing a differentiated phenotype: role of peroxisome proliferator-activated receptor y. Journal of Pharmacy and Pharmacology, 66 (6). pp. 779-792. ISSN 00223573 doi: https://doi.org/10.1111/jphp.12203 Available at https://centaur.reading.ac.uk/40518/

It is advisable to refer to the publisher's version if you intend to cite from the work. See Guidance on citing.

To link to this article DOI: http://dx.doi.org/10.1111/jphp.12203

Publisher: Royal Pharmaceutical Society 
including copyright law. Copyright and IPR is retained by the creators or other copyright holders. Terms and conditions for use of this material are defined in the End User Agreement.

\section{www.reading.ac.uk/centaur}

\section{CentAUR}

Central Archive at the University of Reading

Reading's research outputs online 
TITLE: Ibuprofen inhibits migration and proliferation of human coronary artery smooth muscle cells by inducing a differentiated phenotype: Role of peroxisome proliferator-activated receptor $Y$

AUTHORS: Abeer Dannoura*, Alejandro Giraldo*, Ines Pereira, Jonathan M. Gibbins, Philip R. Dash, Katrina A. Bicknell and Gavin Brooks.

School of Pharmacy, University of Reading (A.D., I.P., K.A.B.,), School of Biological Sciences (A.G., J.M.G., P.R.D., G.B) University of Reading, Institute for Cardiovascular and Metabolic Research, University of Reading, Whiteknights Campus (A.D., A.G., J.M.G., P.R.D., K.A.B., G.B), RG6 6UR, United Kingdom.

E-mails: Abeer Dannoura: adannoura@yahoo.co.uk; Alejandro Giraldo: a.giraldoramirez@reading.ac.uk; Ines Pereira:inesgdapereira@gmail.com; Jonathan M. Gibbins: j.m.gibbins@reading.ac.uk; Phil R. Dash: p.r.dash@reading.ac.uk; Katrina A. Bicknell: k.bicknell@reading.ac.uk; Gavin Brooks: g.brooks@reading.ac.uk.

Keywords: CAD, coronary artery disease; DES, drug eluting stent; HCASMCs, human coronary artery smooth muscle cells; HCAECs, human coronary artery endothelial cells; NSAIDs, non-steroidal antinflammatory drugs; $\mathrm{PCl}$, percutaneous coronary intervention; PPAR, peroxisome proliferator activated receptor.

*these authors contributed equally to this work 
Running title: Ibuprofen modulates human VSMC phenotype

Correspondence: Professor Gavin Brooks, Address: University of Reading, Whiteknights, PO Box 217, Reading, Berkshire, RG6 6AH, United Kingdom. Telephone: +44-(0)118-3786140, Fax: +44-(0)118-987-4062, E-mail: g.brooks@reading.ac.uk. 


\section{Abstract}

Objectives: The search for agents that are capable of preventing restenosis and reduce the risk of late thrombosis is of utmost importance. In this study we aim to evaluate the in vitro effects of ibuprofen on proliferation and migration of human coronary artery smooth muscle cells (HCASMCs) and on human coronary artery endothelial cells (HCAECs) migration.

Methods: Cell proliferation was evaluated by direct cell counting using trypan blue exclusion. Cell migration was assessed by wound healing "scratch" assay and by time lapse videomicroscopy. Protein expression was assessed by immunoblotting, and morphological changes were studied by immunocytochemistry. The involvement of the PPARY pathway was studied with the selective agonist troglitazone, and the use of selective antagonists of PPARy such as PGF2 $\alpha$ and GW9662.

Results: We demonstrate that ibuprofen inhibits proliferation and migration of HCASMCs and induces a switch in HCASMCs towards a differentiated and contractile phenotype, and that these effects are mediated through the PPARY pathway. Importantly we also show that the effects of ibuprofen are cell type specific as it does not affect migration and proliferation of endothelial cells.

Conclusions: Taken together, our results suggest that ibuprofen could be an effective drug for the development of novel drug eluting stents, which could lead reduced rates of restenosis and potentially other complications of DES stent implantation. 


\section{Introduction}

Cardiovascular disease (CVD) remains the leading cause of morbidity and mortality worldwide, accounting for the death of one in three people each year. ${ }^{[1,2]}$ Of the 17.3 million deaths per year due to CVD, coronary artery disease (CAD) was responsible for over $40 \%$ of cases. ${ }^{[2]}$ Current treatment modalities for $C A D$ include percutaneous coronary intervention $(\mathrm{PCl})$ with balloon angioplasty and stent implantation. However, despite advances in stent technology (e.g. drug eluting stents (DES)) that reduced substantially the rates of restenosis to less than $10 \%,{ }^{[3,4]}$ the rates of late in-stent thrombosis, a devastating complication in terms of morbidity and mortality, are higher with DES compared to bare metal stents. ${ }^{[5]}$ Recent reports suggest that the risk of late-stent thrombosis appears to be steadily present over time,$^{[6,7]}$ and, indeed, there have been reports of these events occurring 4.5 to 5 years after DES implantation. ${ }^{[8,9]}$ Thus, late in-stent thrombosis remains a major problem in clinical practice. ${ }^{[10,11]}$ DES contain antiproliferative agents (e.g. rapamycin or paclitaxel), which target vascular smooth muscle cells (VSMCs) and inhibit their migration and proliferation to the site of injury following stent deployment, thus ultimately preventing neointimal formation and restenosis. However, DES also interfere with re-endothelialization of the stent struts, which currently is thought to play a central role in the pathogenesis of very late (>12 months) in-stent thrombosis observed with DES. ${ }^{[12,13]}$ With this in mind, the search for compounds capable of selectively inhibiting migration and proliferation of VSMCs, but sparing endothelial cell (EC) migration and proliferation, for use in DES is of utmost importance.

During restenosis following stent deployment, VSMCs undergo significant changes in morphology and function exhibiting a "synthetic" or "dedifferentiated" phenotype, whereby these cells synthesize components of the extracellular matrix and exhibit characteristics similar to immature cells found in blood vessels during development. ${ }^{[14,15]}$ In the intact vessel wall, however, VSMCs exhibit a "differentiated" or contractile phenotype characterized by a spindle shape and increased expression of contractile proteins, which correlates with increased contractile ability. ${ }^{[15]}$ 
Peroxisome proliferator-activated receptor $\mathrm{Y}$ (PPARY) is a member of the nuclear hormonereceptor superfamily. ${ }^{[16]}$ PPARy expression has been shown to increase in the intima in response to injury. ${ }^{[17]}$ It has been proposed that increased activity of PPARY in blood vessels is important for limiting neointimal formation by enhancing the differentiation of VSMCs and thereby reducing their migratory ability. ${ }^{[18]}$ Previous studies from our laboratory, and others, have demonstrated that ibuprofen, as well as certain other non-steroidal anti-inflammatory drugs (NSAIDs), reduces VSMC proliferation in a dose- and cell cycle-dependent manner. ${ }^{[19,}$ ${ }^{20]}$ In addition, several lines of evidence indicate that NSAIDs, including ibuprofen, have the ability to activate PPARy receptors in several cell types and tissues. ${ }^{[21-23]}$ Here, we confirm that ibuprofen inhibits proliferation and report for the first time that ibuprofen inhibits migration of human coronary artery smooth muscle cells (HCASMCs), and that this correlates with the induction of a differentiated phenotype in these cells. We also report that at least some of the effects of ibuprofen on HCASMCs are mediated through PPARy. More importantly, we also show for the first time that the effect of ibuprofen is cell type specific as it does not affect migration and proliferation of endothelial cells. Taken together, our results suggest that ibuprofen could be a potential molecule for incorporation into DES which may prevent restenosis without interfering with the process of re-endothelialization, thus having the potential of preventing other complications stent implantation. 


\section{Materials and Methods}

\section{Antibodies and reagents}

Antibodies raised against SMa-actin (ab5694), SM22a (ab14106), GAPDH (ab8245), $\beta$-actin (ab6276) and Lamin A (ab8980) were from Abcam (UK); antibody raised against PPARY (sc7273) was from Santa Cruz Biotechnology (USA), antibody raised against ATF-2 (9226) was from Cell Signalling Technology (USA). Alexa Fluor 488 goat anti-mouse (A-11001), Alexa Fluor 594 phalloidin (A12381) and prolong ${ }^{\circledR}$ Gold anti-fade reagent with DAPI (P36935) were from Life Technologies (UK). Most chemicals, including ibuprofen and troglitazone were obtained from Sigma (UK); Mitomycin C was from Calbiochem (UK); GW9662 was obtained from Biomol (UK); PGF2 $\alpha$ was from Merck Chemicals (UK). Tissue culture plates and dishes were from Thermo Fisher Nunc.

\section{Cell culture}

Primary human coronary artery smooth muscle cells (HCASMCs) and primary human coronary artery endothelial cells (HCAECs) were purchased from PromoCell $(\mathrm{GmbH}$, Heidelberg, Germany), and cultured according to manufacturer's instructions using PromoCell's smooth muscle cell growth medium 2 (C-22062) or endothelial cell growth medium MV2 (C-22022), both of which contains 5\% serum without antibiotics or antifungal agents. Passaging was according to the manufacturer's instructions using DetachKit, also from PromoCell. Primary human pulmonary microvascular endothelial cells (HPMECs) were purchased from PromoCell (GmbH, Heidelberg, Germany). Growth media for HPMECs was prepared to give a final concentration of $20 \%(\mathrm{v} / \mathrm{v})$ serum, and a concentration of $50 \mu \mathrm{g} / \mathrm{mL}$ endothelial cell growth supplement in M199 with GlutaMAX ${ }^{\mathrm{TM}}$ medium.

For all experiments, cells were used between passages 3-5 and were cultured replacing with the same fresh growth medium described above. For proliferation assays, HCASMCs $\left(1 \times 10^{4} / \mathrm{ml}\right)$ and HPMECs $\left(1 \times 10^{4} / \mathrm{ml}\right)$ were seeded in 6 -well plates. For wound healing 
assays, HCASMCs $\left(4 \times 10^{4} / \mathrm{ml}\right)$ and HCAECs $\left(5 \times 10^{4} / \mathrm{ml}\right)$ were seeded overnight in 12 -well plates to form a confluent monolayer. For time-lapse video microscopy experiments, both HCASMCs and HCAECs were seeded overnight at $\left(1 \times 10^{4} / \mathrm{ml}\right)$ in 12 -well plates. For immunoblotting, HCASMCs $\left(2 \times 10^{5}\right)$ and HCAECs $\left(3 \times 10^{5}\right)$ were plated in $60 \mathrm{~mm}$ tissue culture dishes. For immunostaining experiments, glass cover slides were placed in 12-well plates and coated with sterile $1 \%(\mathrm{v} / \mathrm{v})$ gelatin in PBS, then washed in PBS and HCASMCs seeded at a density of $1 \times 10^{4} / \mathrm{ml}$.

\section{Proliferation analysis}

Following an initial $24 \mathrm{~h}$ incubation, media was replaced without agonists (vehicle controls) or treated with different doses of ibuprofen. After a further $72 \mathrm{~h}$, direct cell counting was performed by trypan blue exclusion. ${ }^{[20]}$

\section{Wound healing assay}

Migration was investigated using a wound healing "scratch" assay as described before ${ }^{[24,25]}$ with minor modifications. Briefly, $24 \mathrm{~h}$ after plating both HCASMCs and HCAECs at the desired cell density, medium was replaced in the absence (control) or presence of different concentrations of ibuprofen or troglitazone, and in some instances with the selective PPARY inhibitors, GW9662 or PGF2 ${ }^{[26-28]}$ Mitomycin C, was added one hour before scratching at a concentration of $0.5 \mu \mathrm{g} / \mathrm{ml}$. This concentration of mitomycin C completely blocks proliferation of HCASMCs within $1 \mathrm{~h}$ of administration (data not shown). A scratch in the cell monolayer was then generated with a sterile $200 \mu$ micropipette tip and images of the gap were captured immediately (time $0 \mathrm{~h}$ ) and repeated at $24 \mathrm{~h}$ (HCASMCs) or $10 \mathrm{~h}$ (HCAECs) using a phase contrast microscope with an attached ProgRes SpeedXT core 5 digital camera (Jenoptik Systems $\mathrm{GmbH}$ ) with ProgRes CapturePro 2.8.8. The extent of closure of the gap 
(HCAECs) or migrated cell number (HCASMCs) was analysed using ImageJ $(\mathrm{NIH}$, Bethesda).

\section{Time lapse videomicroscopy}

Time lapse video microscopy was used for in vitro real time analysis of HCASMCs and HCAECs migration, as described before ${ }^{[29]}$ with minor modifications. Cells were re-fed with fresh medium in the absence (control) or presence of agonists such as ibuprofen or troglitazone, plus in some instances antagonists, such as GW9662. Following treatments for $30 \mathrm{~min}$, cells were tracked for $48 \mathrm{~h}$ at $15 \mathrm{~min}$ intervals. Over 90 cells were tracked in each of three separate wells per condition, with images captured by a Nikon digital camera DXM 1200 Japan (NIS-elements AR software). All microscopy stages were performed in a controlled environment $\left(37^{\circ} \mathrm{C}\right.$ and $\left.5 \% \mathrm{CO}_{2}\right)$. The distance that a particular cell had migrated within $48 \mathrm{~h}$ was analysed using Image software (NIH, Bethesda).

\section{Immunoblotting}

Whole cell extracts were prepared as described previously with minor modifications. ${ }^{[20]}$ Briefly, HCASMCs or HCAECs were washed gently in ice cold PBS and scraped into $150 \mu \mathrm{l}$ protein lysis buffer [50 mM Tris $\mathrm{HCl}$ pH 7.4, $250 \mathrm{mM} \mathrm{NaCl}, 5 \mathrm{mM}$ EDTA pH 8.0, with freshly added Igepal $(0.1 \% \mathrm{v} / \mathrm{v})$ ], supplemented with protease inhibitors [0.3 $\mathrm{mM} \mathrm{AEBSF}, 10 \mu \mathrm{g} / \mathrm{ml}$ Leupeptin and $2 \mu \mathrm{g} / \mathrm{ml}$ Aprotinin]. Samples were incubated on ice for $10 \mathrm{~min}$ and then centrifuged $\left(10,000 \times \mathrm{g}, 5 \mathrm{~min}, 4^{\circ} \mathrm{C}\right)$. Supernatants were transferred to fresh micro tubes and stored at $-80^{\circ} \mathrm{C}$ until use.

Nuclear extracts were prepared as described previously, with minor modifications. ${ }^{[30,31]}$ Briefly, HCASMCs or HCAECs were washed gently in ice cold PBS and scraped into $150 \mu \mathrm{l}$ ice cold nuclear buffer A [10 mM HEPES pH 7.9, $10 \mathrm{mM} \mathrm{KCl}, 1.5 \mathrm{mM} \mathrm{MgCl}, 0.3 \mathrm{mM}$ 
$\mathrm{Na}_{3} \mathrm{VO}_{4}$ ], supplemented with protease inhibitors $(0.3 \mathrm{mM}$ AEBSF, $10 \mu \mathrm{g} / \mathrm{ml}$ Leupeptin and 2 $\mu \mathrm{g} / \mathrm{ml}$ Aprotinin). Samples were incubated on ice for $5 \mathrm{~min}$, then centrifuged $(10,000 \times \mathrm{g}, 5$ min, $\left.4^{\circ} \mathrm{C}\right)$ and the pellets washed in $100 \mu \mathrm{l}$ nuclear buffer $A$ containing Igepal $(0.1 \% \mathrm{v} / \mathrm{v})$. Samples were incubated for $5 \mathrm{~min}$ on ice, then centrifuged $\left(10,000 \times \mathrm{g}, 5 \mathrm{~min}, 4^{\circ} \mathrm{C}\right)$ and the pellets re-suspended in $50 \mu \mathrm{l}$ nuclear buffer C [20 mM HEPES pH 7.9, $420 \mathrm{mM} \mathrm{NaCl}, 1.5$ $\mathrm{mM} \mathrm{MgCl} 2,0.3 \mathrm{mM} \mathrm{Na}_{3} \mathrm{VO}_{4}, 0.2 \mathrm{mM}$ EDTA pH 8.0, 25\% (v/v) glycerol] supplemented with protease inhibitors as above. Suspensions were incubated on ice for $1 \mathrm{~h}$ with gentle vortexing every $15 \mathrm{~min}$, then centrifuged $\left(10,000 \times \mathrm{g}, 5 \mathrm{~min}, 4^{\circ} \mathrm{C}\right)$. Supernatants were transferred to fresh micro tubes and stored at $-80^{\circ} \mathrm{C}$ until use. Protein concentrations were determined by the Bradford method. ${ }^{[32]}$

Samples were boiled with 0.33 vol of SDS-polyacrylamide gel electrophoresis sample buffer [10\% SDS (w/v), 13\% glycerol v/v), $300 \mathrm{mM}$ Tris $\mathrm{HCl}, \mathrm{pH} 6.8,130 \mathrm{mM}$ DTT, $0.2 \%$ bromophenol blue $(\mathrm{w} / \mathrm{v})]$. Proteins $(20 \mu \mathrm{g})$ were separated by SDS-polyacrylamide gel electrophoresis using $10 \%(\mathrm{w} / \mathrm{v})$ resolving gels and $6 \%(\mathrm{w} / \mathrm{v})$ stacking gels, and transferred to nitrocellulose as described previously. ${ }^{[11]}$ Nonspecific binding sites were blocked with $5 \%$ (w/v) non-fat milk powder in TBS-T [20 mM Tris $\mathrm{HCl} p H$ 7.5, $137 \mathrm{mM} \mathrm{NaCl}, 0.1 \%$ (v/v) Tween 20]. Membranes were incubated (overnight, $4{ }^{\circ} \mathrm{C}$ ) with primary antibodies diluted (1:1000 for PPARy to 1:20000) in TBS-T containing 5\% non-fat milk powder for most antibodies, except PPARy and ATF2 which were incubated in $5 \%(\mathrm{w} / \mathrm{v})$ bovine serum albumin. Membranes were washed in TBS-T, incubated (60 min, room temperature) with horseradish peroxidase- (HRP-) conjugated secondary antibodies from Dako (1/5000 to 1:25000 dilutions) in TBS-T containing 1\% (w/v) non-fat milk powder, and were then washed in TBS-T. Bands were detected using enhanced chemiluminescence (ECL) Prime (GE Healthcare) and an ImageQuant LAS4000 mini digital imager (GE Healthcare). ImageQuant 8.1 (GE Healthcare) software was used for densitometric analysis.

\section{Immunocytochemistry}


HCASMCs were exposed to $500 \mu \mathrm{M}$ ibuprofen for $72 \mathrm{~h}$, then washed with PBS and fixed in $4 \%(\mathrm{v} / \mathrm{v})$ formaldehyde (10 min at room temperature). Following permeabilization with $0.1 \%$ Triton X-100 in PBS (10 min at room temperature) and incubation with $1 \%(\mathrm{w} / \mathrm{v})$ BSA in PBS containing $0.1 \%$ Triton $\mathrm{X}-100$ (20 min at room temperature) to block non-specific antibody binding, immunocytochemistry was performed as described previously with minor modifications. $^{[31]}$ Briefly, cover slides were incubated with mouse monoclonal primary antibodies against $\beta$-actin $(1: 1000$ dilution for $60 \mathrm{~min}$ at $37 \circ \mathrm{C})$, followed by Alexa Fluor ${ }^{\circledR} 488$ anti-mouse secondary antibodies $\left(1 / 200\right.$ dilution for $\left.60 \mathrm{~min}, 37^{\circ} \mathrm{C}\right)$, and then incubated with Alexa Fluor ${ }^{\circledR} 594$ phalloidin $(1: 200$ dilution for $20 \mathrm{~min}$ at $37 \circ \mathrm{C})$. Washes $(\times 3)$ were performed with PBS between incubations. After the final wash, cover slides were mounted with prolong ${ }^{\circledR}$ Gold anti-fade reagent with DAPI (Invitrogen) and visualized using a Zeiss AX10 Axioskop fluorescence microscope. Images were captured using a Zeiss AxioCam MRm digital camera with Software AxioVision Rel 4.8.2 (Carl Zeiss Microlmaging GmbH). Colour images were converted to greyscale using Adobe Photoshop.

\section{Statistical Analysis}

Statistical analysis was performed with Graphpad Prism 5.0. The data are presented as mean \pm SEM, and significance of results was determined by one-way ANOVA with Dunnet's or Tukey's post test, and, where appropriate, a paired two-tailed student $t$ test. The results were considered significant when $p<0.05$. 


\section{Results}

Proliferation and migration of HCASMCs is inhibited by ibuprofen in a dose dependent manner

Proliferation and migration of VSMCs are key elements in the pathophysiology of restenosis post-stent implantation. ${ }^{[33]}$ Previous studies from our laboratory demonstrated that $\mathrm{A} 10$ rat VSMC proliferation was inhibited by several NSAIDs in a dose-dependent manner ${ }^{[20]}$ Here, we first evaluated whether proliferation of human primary HCASMCs is similarly affected by ibuprofen. Treatment with different concentrations of ibuprofen did, indeed, cause an inhibitory effect on the proliferation of HCASMCs in a dose-dependent manner. Thus, whilst $100 \mu \mathrm{M}$ ibuprofen had no significant effect, concentrations above $250 \mu \mathrm{M}$ progressively inhibited proliferation of HCASMCs, with an $\mathrm{IC}_{50}$ of $680 \pm 120 \mu \mathrm{M}$ (Figure $\left.1 \mathrm{~A}\right)$.

We then performed in vitro studies to evaluate the effects of ibuprofen on the migration of HCASMCs. Using a wound healing "scratch" assay (a well validated method for evaluating migration of cells in vitro), ${ }^{[25]}$ we first observed that HCASMCs migrate individually rather than as a population of cells. Subsequent observations indicated that ibuprofen inhibits the number of cells that migrate to the wound in a dose-dependent manner. Thus, doses up to $2000 \mu \mathrm{M}$ ibuprofen were able to inhibit the migrated cell number with an $\mathrm{IC}_{50}$ of $410 \pm 60 \mu \mathrm{M}$ (Figures 1B and 1C), without significant cytotoxicity for the cells (as determined by trypan blue exclusion assay; data not shown).

We then used time-lapse videomicroscopy to evaluate, in real time, the effects of ibuprofen on migration of HCASMCs. Ibuprofen $(500 \mu \mathrm{M})$, caused a significant reduction in the average mean displacement by HCASMCs over a period of $48 \mathrm{~h}$ (Figure 2), further confirming the ability of ibuprofen to inhibit migration of HCASMCs cells in vitro.

\section{Ibuprofen induces a phenotypic switch in HCASMCs}


Previous studies have shown that, during culture in the presence of serum, VSMCs become de-differentiated, adopting an amoeboid shape and exhibiting increased synthesis of components of the extracellular matrix, thus the term "synthetic" that is commonly used to describe this phenotype. ${ }^{[34]}$ Associated with this change in phenotype, de-differentiated VSMCs also show a reduced expression of contractile proteins, including SMa-actin, SM22a and F-actin. ${ }^{[33,34]}$ In contrast, serum starvation or treatment with rapamycin, induces differentiation of VSMCs with a characteristic spindle shape and increased expression of contractile proteins, giving rise to the commonly used term, "contractile" phenotype ${ }^{[33-35]}$ Importantly, during vascular damage (e.g. stent deployment), VSMCs migrate and proliferate to the site of injury, and this correlates with a change from a contractile towards a synthetic phenotype..$^{[15]}$

Given the effects of ibuprofen on the proliferation and migration of HCASMCs, we tested the possibility that these effects correlate with a change in the de-differentiation state of these cells. Therefore, we investigated the morphology of HCASMCs using immunocytochemistry. Treatment with $500 \mu \mathrm{M}$ ibuprofen for $72 \mathrm{~h}$ induced a change in morphology, from an amoeboid into a spindle shape (Figure $3 \mathrm{~A}$ ). Characteristically, the observed change in cell surface area induced by ibuprofen mainly affects the width of the treated cell whereas the length of the cell remains unchanged (Figure 3B-3D).

We next investigated whether the changes in morphology induced by ibuprofen correlated with changes in expression of markers of the differentiated state. ${ }^{[34]}$ HCASMCs cultured in the presence of serum, were either untreated (vehicle controls) or exposed to ibuprofen 500 $\mu \mathrm{M}$, and the protein levels of SMa-actin and SM22 $\alpha$ were then assessed by immunoblotting analysis. As shown in Figure 4A-C, the protein levels of SMa-actin and SM22a were upregulated following treatment with ibuprofen for 72 hours. When we analyzed the myofilament density of HCASMC, it revealed that treatment with ibuprofen increased the phalloidin staining intensity of F-actin, another marker of differentiation of VSMCs, ${ }^{[34]}$ as 
compared with untreated, vehicle controls (Figure 4D), further supporting the possibility that ibuprofen induces a switch from a synthetic to a contractile phenotype in HCASMCs.

\section{The effects of ibuprofen on HCASMCs are partially mediated by PPARY}

Many effects of NSAIDs are mediated via cyclooxygenase (COX)-independent mechanisms; ${ }^{[36]}$ indeed, previous studies have demonstrated that ibuprofen and other NSAIDs are agonists of PPARy. ${ }^{[21-23]}$ On the other hand, the major metabolite of arachidonic acid via COX in VSMCs is PGF2 $\alpha^{[37]}$ Interestingly, PGF2 $\alpha$ is a selective antagonist of PPARy. ${ }^{[26,27]}$ To study the molecular mechanisms of the effects of ibuprofen in HCASMCs, we evaluated whether the selective natural antagonist of PPARy, PGF2 $\alpha,{ }^{[26,27]}$ or the selective synthetic antagonist, GW9662, ${ }^{[28]}$ could prevent the effects of ibuprofen in HCASMCs.

Figure (5A) shows that the inhibitory effect of ibuprofen on proliferation of HCASMCs was almost completely abrogated by pre-incubation with either PGF2 $\alpha$ or GW9662. Similarly, analysis of migration by wound healing "scratch" assay and time-lapse video-microscopy in the presence of either PGF2a or GW9662 in combination with ibuprofen, suggest that the PPARY pathway is also involved in mediating the effects of ibuprofen on HCASMC migration (Figures $5 \mathrm{~B}$ and $5 \mathrm{C}$ ). Thus, whereas incubation with either antagonist alone does not significantly affect the migration of HCASMCs compared to control conditions, incubation of HCASMCs with ibuprofen in the presence of either PGF2 $\alpha$ or GW9662 significantly, but not completely reverses the effects of ibuprofen (Figures $5 B$ and $5 C$ ).

We then explored whether the effects of ibuprofen on morphology and expression of markers of differentiation in HCASMCs were also mediated via PPARY. As shown in Figures $3 \mathrm{~A}$ and $3 \mathrm{~B}$, cell surface area in HCASMCs treated with ibuprofen in combination with GW9662 (3 $\mu \mathrm{M})$ was similar to that of medium alone-treated control cells, and was significantly higher than those treated with ibuprofen alone, suggesting that PPARY does, 
indeed, play a role in the phenotype switch induced by ibuprofen. However, whilst GW9662 significantly inhibits the effects on morphology induced by ibuprofen, they do not return to levels seen in untreated, control cells (Figures $3 A$ and $3 B$ ), suggesting that other pathways might also be involved in mediating these morphological effects. Indeed, troglitazone, a selective PPARY agonist, induces changes in the morphology of HCASMCs but these are qualitatively different to those induced by ibuprofen (Figure $3 \mathrm{~A}$ ). Thus, whilst ibuprofen induces a change in morphology resembling the characteristic spindle shape of

differentiated VSMCs as described previously, ${ }^{[34,35]}$ troglitazone affects both cell width and cell length in HCASMCs as opposed to ibuprofen that mainly affects cell width without affecting cell length (Figures 3A-3D). Finally, we evaluated the expression of protein markers of VSMC differentiation. Significantly, whilst ibuprofen induced expression of both SMa-actin and SM22 $\alpha$ (Figures 4A-4C, 6A-6C), incubation with PGF2 $\alpha$ did not significantly inhibit these effects. In fact, SM22 $\alpha$ expression levels in the presence of PGF2 $\alpha$ alone, or in combination with ibuprofen, did not differ; the effect of troglitazone was comparable to that of ibuprofen (Figures $6 \mathrm{~A}$ and $6 \mathrm{C}$ ). In contrast, whereas PGF2 $\alpha$ had a trend to inhibit the effects of ibuprofen on SMa-actin expression, this was not significant, and troglitazone failed to induce expression of this protein above control levels (Figures 6A and 6B).

\section{Ibuprofen does not affect migration and proliferation of endothelial cells}

Taken together, our results suggest that ibuprofen inhibits proliferation and migration of HCASMCs and this is partially mediated by the PPARY pathway. In clinical practice, the ideal DES would prevent restenosis and also late and very late in-stent thrombosis. It has been suggested that the currently available DES target VSMC migration and proliferation, but in doing so they also prevent re-endothelialisation of the stent struts, with the risk of very late in-stent thrombosis steadily occurring over time,${ }^{[6,7]}$ indicating that complete healing of the vessel wall is never achieved. Novel DES that prevent migration and proliferation of VSMCs whilst permitting the migration and proliferation of ECs, and thus allowing re- 
endothelialization, could offer a significant advantage for DES stent therapy. Therefore, we performed "scratch" wound assays and time-lapse videomicroscopy analysis to evaluate the effects of ibuprofen on migration of HCAECs.

As shown in Figure 7A, ibuprofen at all concentrations tested $(100-1000 \mu \mathrm{M})$ does not significantly affect migration of HCAECs as measured via a "scratch" wound assay. Similarly, ibuprofen at a concentration of $750 \mu \mathrm{M}$, which potently inhibits migration of HCASMCs (Figure 1B and Figure 2), fails to inhibit migration of HCAECs as demonstrated by time-lapse videomicroscopy analysis (Figure 7B). In contrast, troglitazone does affect migration of HCAECs as measured by wound healing assay and time lapse videomicroscopy (Figure 7A and Figure 7B). We also evaluated the effects of ibuprofen on proliferation of HPMECs. Whilst doses of $100-1000 \mu \mathrm{M}$ had no significant effect on proliferation of these cells, there was significant inhibition of proliferation at doses of 2000 $\mu \mathrm{M}$, with an estimated $\mathrm{IC}_{50}$ of $1500 \pm 50 \mu \mathrm{M}$ (Figure $7 \mathrm{C}$ ). Interestingly, this $\mathrm{IC}_{50}$ is up to three times higher than that required to inhibit HCASMCs proliferation. Taken together, these experiments suggest that the effect of ibuprofen on migration and proliferation at doses below $2000 \mu \mathrm{M}$ is cell type specific thus affecting only HCASMCs while sparing migration and proliferation of ECs.

We next compared the expression levels of PPARy in both HCASMCs and HCAECs. First, we were able to determine that PPARy, as a nuclear receptor protein, was present mainly in the nuclear fractions of both cell types (Figure $8 \mathrm{~A}$ ). To verify the loading of nuclear fractions, membranes were probed with ATF2 antibody, and, as shown in Figures $8 \mathrm{~B}$ and $8 \mathrm{C}$, densitometric analysis showed that PPARY was more abundant in HCASMCs than in HCAECs when levels were normalized to the loading control, ATF2 (Figures 8B and 8C). Interestingly the protein expressed in both cell types had a molecular mass of $\approx 53 \mathrm{kDa}$ (see Discussion). 


\section{Discussion}

Restenosis post stent implantation is a complex pathophysiological process, which involves proliferation and migration of VSMCs to the site of injury (e.g. following balloon angioplasty and stent deployment) and a change in VSMCs towards a synthetic/proliferative phenotype. ${ }^{[33]}$ Indeed, the restenotic vessel wall is mostly composed of extracellular matrix proteins synthetized by dedifferentiated proliferative VSMCs. ${ }^{[14]}$ Recent advances in stent technology, including DES containing antiproliferative agents (e.g. rapamycin and paclitaxel) have reduced significantly the rate of restenosis to less than $10 \%$ over the past decade. ${ }^{[3,4]}$ However, despite the success of DES in reducing restenosis rates, there is a constant threat of late and very late in-stent thrombosis, particularly following abrupt discontinuation of dual antiplatelet therapy. ${ }^{[5]}$ Several factors appear to be implicated in the biology of late in-stent thrombosis, but most evidence suggests it is the lack of selectivity of DES targeting not only VSMCs but also endothelial cells, thus interfering with the process of re-endothelialisation and vessel wall repair. ${ }^{[12,13]}$ Thus, novel compounds capable of selectively targeting VSMCs migration and proliferation without interfering with the process of re-endothelialization are urgently needed. Indeed, the ideal stent should be capable of maintaining low rates of restenosis, reducing the risk of early or late in stent thrombosis, and promoting vessel wall healing by modulating the inflammatory response within the vessel wall. ${ }^{[15,38]}$ Several second generation DES, containing everolimus, or zotarolimus, share the molecular mechanisms of their predecessor, sirolimus (rapamycin), and therefore target VSMCs as well as endothelial cells. Whilst recent clinical trials suggest improved outcomes compared to first generation DES up to 2 years of follow up, ${ }^{[39]}$ their performance in terms of late complications such as late and very late (>12 months) stent thrombosis remain to be determined.

We, and others, have previously shown that certain NSAIDs, including the propionic acid derivative, ibuprofen, are capable of reducing rat VSMCs proliferation in a dose- and cell cycle-dependent manner. ${ }^{[19,20]}$ Here, we studied the ability of ibuprofen to inhibit proliferation 
and migration of HCASMCs. First, we demonstrated that ibuprofen was able to inhibit both proliferation and migration of HCASMCs in a dose-dependent manner. Of note, the concentration required to inhibit proliferation of HCASMCs $\left(\mathrm{IC}_{50} 680 \pm 120 \mu \mathrm{M}\right)$ is similar to the dose that inhibited A10 rat VSMCs proliferation in our previous study $\left(\mathrm{IC}_{50} 646 \mu \mathrm{M}\right) .{ }^{\left[{ }^{[20]} \mathrm{A}\right.}$ similar concentration range is required for inhibition of HCASMC migration (IC $50410 \pm 60 \mu \mathrm{M})$ as demonstrated by wound healing "scratch" assay and also by time lapse video microscopy. Interestingly, we also found that the effects of ibuprofen on HCASMC migration and proliferation correlated with the induction of a phenotypic switch on HCASMCs towards a differentiated, contractile state, characterized by a spindle shape morphology and increased expression of known contractile protein markers of differentiation. ${ }^{[33-35]}$

Accumulating evidence indicates that NSAIDs have pleiotropic effects in many cell types, and therefore may have a therapeutic role in several conditions including prevention and treatment of certain types of cancer, $^{[36]}$ and in prevention and treatment of neurodegenerative diseases, such as Alzheimer disease. ${ }^{[22]}$ It has been demonstrated previously that Ibuprofen, as well as other NSAIDs, activate PPARY in several cell types. ${ }^{[21,}$ ${ }^{40]}$ Indeed, Ibuprofen at the dose range used in our studies, has been shown to activate the PPARY pathway. ${ }^{[23,41]}$ In addition, ibuprofen reduces glial inflammation via a PPARYdependent mechanism, thus explaining the beneficial effects of ibuprofen and other NSAIDs in Alzheimer's disease. ${ }^{[23,42]}$ The report of Weber et al (2000), suggests that the effects of ibuprofen on VSMCs proliferation are COX-independent. ${ }^{[19]}$ Significantly, PPARY appears to be protective in the cardiovascular system, and has important regulatory roles in vascular biology. ${ }^{[43]}$ Our data indicate that ibuprofen-induced inhibition of HCASMC proliferation appears to be mediated primarily by the PPARY pathway, since pre-incubation with the selective PPARy antagonists, PGF2 $\alpha$ and GW9662, almost completely restored the proliferative ability of HCASMCs to control levels. To our knowledge, only few studies have aimed to elucidate the mechanisms whereby NSAIDs inhibit VSMCs proliferation. One study found that several NSAIDs, including ibuprofen, inhibit A10 VSMCs proliferation via inhibition 
of store operated $\mathrm{Ca} 2+$ entry (SOCE) channels, an important $\mathrm{Ca} 2+$ entry pathway involved in cell proliferation. ${ }^{[44]}$ Another study showed that aspirin inhibited VSMCs proliferation by inducing phosphorylation of AMP-activated protein kinase. ${ }^{[45]}$ The precise mechanisms whereby ibuprofen via activation of PPARY inhibit proliferation in VSMCs remain to be elucidated; further studies are needed to clarify this. Several agonists of PPARY have been described including thiazolidinediones (e.g. ciglitazone, troglitazone, pioglitazone, rosiglitazone), and natural ligands including prostanoids, such as $15 \mathrm{~d}-\mathrm{PGJ} 2$, as well as n3polyunsaturated fatty acids. ${ }^{[43]}$ These PPARY agonists appear to inhibit VSMCs proliferation via downstream mechanisms that include, inhibiting the expression of the transcription factor C-fos, ${ }^{[46,47]}$ blockade of Angiotensin-II induced activation of extracellular signal-regulated kinase $1 / 2(E R K 1 / 2),{ }^{[18,48,49]}$ and suppression of cell cycle signaling through decreased phosphorylation of the retinoblastoma protein $(\mathrm{Rb}),{ }^{[50]}$ a mediator of $\mathrm{G} 1 / \mathrm{S}$ progression, and prevention of mitogen induced degradation of $\mathrm{p} 27(\mathrm{Kip} 1),{ }^{[50]}$ an inhibitor of cdk and Rb phosphorylation.

The ibuprofen-induced phenotypic switch in HCASMCs also appears to be mediated by PPARy as pre-incubation with GW9662 in the presence of ibuprofen induces a dedifferentiated amoeboid morphology similar to that of control cells, whereas incubation with ibuprofen alone induces a differentiated spindle-shaped morphology. Similarly, PPARY plays an important role in the migratory activity of HACSMCs as suggested by the partial rescue of the migratory activity of these cells by incubation with the PPARY antagonists, PGF2 $\alpha$ and GW9662, in the presence of ibuprofen.

Since the effect of PPARy inhibitors did not completely abrogate the migratory response, other pathways could be involved in this response in addition to PPARY. We speculate that one such pathway could be COX2. Indeed, one of the main metabolites of arachidonic acid in VSMCs is PGF2 $\alpha,{ }^{[37]}$ and this metabolite is a natural selective antagonist of PPARY. ${ }^{[26,27]}$ Similarly, in vivo studies have shown that there is increased expression and activity of COX2 
in the intima following vascular injury. ${ }^{[17,51]}$ Furthermore, the synthesis of PGF2 $\alpha$ via COX activity is increased by PDGF, ${ }^{[52,53]}$ an important regulator of the differentiation state of VSMCs, which induces dedifferentiation of VSMCs towards a synthetic phenotype and promotes their migration and proliferation. ${ }^{[54-56]}$ In agreement with these observations, our preliminary data using the wound healing "scratch" assay, indicate that celecoxib, a COX2 selective inhibitor, at doses that are non-toxic to the cells $(6.25-25 \mu \mathrm{g})$, prevents migration of rat A10 VSMCs whilst sparing HCAECs migration (unpublished observations).

Of note, our data also indicate that migration and proliferation of ECs is not affected by ibuprofen, suggesting that the effect of ibuprofen is cell-type specific. This is an important novel finding form our study and to our knowledge this is the first evidence indicating that a molecular compound such as ibuprofen has the ability to selectively inhibit VSMCs proliferation and migration while sparing ECs proliferation and migration. The potential implications of this observation could translate into the development of novel DES that could have advantages over DES currently in use by not only preventing the development of restenosis but at the same time, by not interfering with migration and proliferation of ECs, facilitate the process of re-endothelialization of the stent struts. The reasons for the selectivity of ibuprofen are not clear. PPARY are ligand-activated transcription factors that belong to a nuclear receptor superfamily, of which two isoforms, PPARY1 (53 kDa) and PPARY2 $(57 \mathrm{kDa})$, are formed from the same gene by alternative mRNA splicing. ${ }^{[57,58]}$ Our results indicate that a single protein band of approximate $53 \mathrm{kDa}$ is detectable in nuclear extracts of both HCASMCs and HCAECs (Figure 8), likely corresponding to the PPARY1 isoform. This is in agreement with previous studies suggesting that only PPARy1 is expressed in VSMCs and endothelial cells of different species and tissues. ${ }^{[59,60]}$ We also observed that the relative expression levels of PPARY appear to be higher in HCASMCs compared to HCAECs, and this could partly explain the sensitivity of HCASMCs to the effects of ibuprofen. 
Drugs currently used in DES including sirolimus, paclitaxel and zotarolimus inhibit proliferation of VSMCs in nano molar concentrations. ${ }^{[61,62]}$ Thus, a potential limitation of our study is that $\mathrm{IC}_{50}$ concentrations of ibuprofen for migration and proliferation appear to be very high which may difficult the feasibility of using ibuprofen in a DES.

Taken together, our results suggest that the in vitro effects of ibuprofen on migration and proliferation, coupled with the induction of a phenotype switch towards a differentiated state whilst sparing migration of HCAECs, could be exploited by the incorporation of ibuprofen into a DES to prevent restenosis post stent implantation and potentially reduce other complications of DES stent implantation by not interfering with migration and proliferation of ECs. Whether our in vitro observations could be translated clinically into a DES of increased performance remains to be demonstrated. Future studies will aim to evaluate the feasibility of ibuprofen-containing DES in in vivo animal models of vascular injury and restenosis.

\section{Conclusion}

In conclusion, this study demonstrates for the first time that ibuprofen induces a phenotypic change in HCASMCs, which is consistent with the reduced proliferative and migratory ability of these cells. The effects of ibuprofen on morphology and proliferation of HCASMCs are mediated mainly by the PPARY pathway. Migration of HCASMCs appears to be mediated in part by PPARY, since pre-incubation with PPARY antagonists significantly, but not completely, reverses the effects of ibuprofen; other pathways (e.g. via COX 2) could be involved in this response. Importantly, migration and proliferation of ECs is not affected by ibuprofen at concentrations that potently inhibit HCASMCs proliferation and migration, indicating that HCASMCs are targeted selectively by ibuprofen. The reasons for the selectivity of ibuprofen affecting HCASMCs whereas it spares migration of HCAECs remain unclear, but the relatively higher expression levels of PPARY in HCASMCs could be, at least in part, responsible for the sensitivity of HCASMCs to this drug. Our in vitro observations 
could translate into reduced rates of restenosis post angioplasty with stent deployment of an ibuprofen containing DES, providing ibuprofen-induced inhibition of proliferation and migration of HCASMCs, and could potentially also lead to a reduced risk of other complications following stent implanation, as ibuprofen spares the migration and proliferation of ECs.

\section{Declarations}

\section{Conflict of interest}

The Author(s) declare(s) that they have no conflicts of interest to disclose.

Funding: This work was supported by University of Reading, United Kingdom, and Tishreen University, Syria.

Authorship contributions: (AD, AG, PD, JMG, KAB, GB) Participated in research design, $(A D, A G, I P)$ conducted experiments, (AD, AG) performed data analysis, $(A D, A G, G B)$ wrote or contributed to the writing of the manuscript.

Footnotes:

* These authors contributed equally to this work.

Reprints request: Professor Gavin Brooks, Address: University of Reading, Whiteknights, PO Box 217, Reading, Berkshire, RG6 6AH, United Kingdom. Telephone: +44-(0)118-3786140, Fax: +44-(0)118-987-4062, E-mail: g.brooks@reading.ac.uk. 


\section{Figure legends}

Fig 1. Ibuprofen inhibits migration and proliferation of HCASMCs. A) HCASMCs were either untreated (vehicle control) or treated with increasing concentrations of ibuprofen (100 - 1000 $\mu \mathrm{M})$. Trypan blue exclusion was used to determine the inhibitory effect of ibuprofen on HCASMC proliferation 72 hours after incubation. Ibuprofen causes inhibition of proliferation in a dose-dependent manner with an $\mathrm{IC}_{50}$ of $680 \pm 120 \mu \mathrm{M}$. B) HCASMCs were either unstimulated (vehicle control), or stimulated with increasing concentrations of ibuprofen for 24h. Mitomycn C was added at $23 \mathrm{~h}$ (1 hour before "scratch" wound) to prevent unwanted proliferation. Wound healing "scratch" assay was then performed as described in Materials and Methods. Ibuprofen causes inhibition of migration in a dose-dependent manner with an $\mathrm{IC}_{50}$ of $410 \pm 160 \mu \mathrm{M}(100-1000 \mu \mathrm{M})$. Data shown in A and B are representative of 3-4 independent experiments. C) Representative images of the effects of ibuprofen (500 $\mu \mathrm{M}$ and $750 \mu \mathrm{M}$ ) versus control on migration of HCASMCs. ${ }^{*} p<0.05$, by one way ANOVA with Dunnett's multiple comparison test.

Fig 2. Ibuprofen inhibits migration of HCASMCs. Time lapse video microscopy of the effects of ibuprofen $(500 \mu \mathrm{M})$ compared to control. Data are presented as bar and whisker graphs and are representative of three independent experiments and are shown as mean \pm SEM of average migrated displacement (AMD). ${ }^{*} p<0.05$ as compared to controls.

Fig 3. Ibuprofen induces a phenotypic switch in HCASMCs. A)-C) HCASMCs were untreated (control) or exposed to troglitazone $(100 \mu \mathrm{M})$ or GW9662 $(3 \mu \mathrm{M})$ alone or in combination with ibuprofen $(500 \mu \mathrm{M})$ for 72 hours. A) Cells were immunostained; pictures are representative of three independent experiments. Scale bar $=50 \mu \mathrm{m}$. B) Areas; C) 
lengths; and, D) widths, were measured for at least 40 cells in each experiment. Results are means \pm SEM for three independent experiments. ${ }^{*} p<0.05,{ }^{* *} p<0.01$ one way ANOVA with Tukey's post test.

Fig 4. Ibuprofen increases the expression of protein markers of differentiation. A) HCASMCs were unstimulated (control) or exposed to $500 \mu \mathrm{M}$ ibuprofen for $72 \mathrm{~h}$ and expression of SM $\alpha$-actin and SM22 $\alpha$ protein levels were assessed by immunoblotting. Images are representative of three independent experiments. B) and C), densitometric analyses of immunoblotts. Data presented as mean \pm SEM for three independent experiments. D) fluorescence intensity analysis of F-actin expression on HCASMCs untreated (control) or exposed to $500 \mu \mathrm{M}$ for 72 hours. F-actin fibers were stained with Alexa Fluor ${ }^{\circledR} 594$ phalloidin. ${ }^{*} p<0.05$ paired two-tailed student $t$ test.

Fig 5. The effects of ibuprofen on proliferation and migration of HCASMCs is mediated via PPARY. A) HCASMCs were either untreated (vehicle controls) or exposed to either PGF2 $\alpha$ (100 nM) or GW9662 (3 $\mu \mathrm{M})$ in the presence or absence of ibuprofen $(500 \mu \mathrm{M})$. Trypan blue exclusion was used to evaluate HCASMC proliferation. B) Cells were untreated (vehicle controls) or exposed to either PGF2a or GW9662 in the presence or absence of ibuprofen $(500 \mu \mathrm{M})$ for $72 \mathrm{~h}$. Mitomycn $\mathrm{C}(0.5 \mu \mathrm{g} / \mathrm{ml})$ was added at 1 hour before the "scratch" wound to prevent unwanted proliferation. Wound healing "scratch" assay was then performed. C) Time lapse video microscopy of the effects of ibuprofen $(500 \mu \mathrm{M})$ on migration of HCASMCs in the presence or absence of GW9662 compared to vehicle controls and troglitazone (100 $\mu \mathrm{M})$. Data are presented as bar and whisker graphs and are representative of three independent experiments and are shown as mean \pm SEM of average migrated displacement (AMD). ${ }^{*} p<$ 0.05 one way ANOVA with Tukey's post test. 
Fig 6. Ibuprofen-mediated expression of protein markers of differentiation is not dependent on PPARy. A) immunoblotting analysis of markers of contractile proteins expressed in HCASMCs in response to troglitazone $(100 \mu \mathrm{M})$, or ibuprofen $500 \mu \mathrm{M}$ alone or in combination with PGF2 $\alpha(100 \mathrm{nM})$ versus vehicle control. B) and C), densitometric analyses of immunoblots relative to GAPDH. Data presented are mean \pm SEM from three independent experiments. ${ }^{*} p<0.05$ one way ANOVA with Tukey's post test.

Fig 7. Ibuprofen does not affect migration and proliferation of endothelial cells. A) HCAECs were untreated, exposed to different concentrations of ibuprofen (100 $\mu \mathrm{M}-1000 \mu \mathrm{M})$, or exposed to troglitazone $(100 \mu \mathrm{M})$ for $24 \mathrm{~h}$. Results shown are mean \pm SEM for three independent experiments. ${ }^{*} p<0.05$ one way ANOVA with Tukey's post test. B) Time lapse video microscopy on HCAECs treated with troglitazone $(100 \mu \mathrm{M})$ or GW9662 (3 $\mu \mathrm{M})$ alone or in combination with ibuprofen $(500 \mu \mathrm{M})$. Data are presented as bar and whisker graphs and are representative of three independent experiments and are shown as mean \pm SEM of average migrated displacement (AMD). C) Human pulmonary microvascular endothelial cells (HPMECs) were either untreated (vehicle control) or treated with increasing concentrations of ibuprofen $(100-2000 \mu \mathrm{M})$. Direct cell counting using Trypan blue exclusion was used to determine the inhibitory effect of ibuprofen on HPMECs proliferation 72 hours after incubation. Ibuprofen causes inhibition of proliferation in a dose-dependent manner with an $\mathrm{IC}_{50}$ of $1500 \pm 50 \mu \mathrm{M}$. ${ }^{*} p<0.05$, by one way ANOVA with Dunnett's multiple comparison test. 
Fig 8. PPARy is mainly a nuclear protein and is more abundantly expressed in HCASMCs relative to HCAECs. A) and B) immunoblotting analysis of PPARy expression in untreated HCASMCs vs HCAECs. A) PPARy is mainly expressed in the nucleus. B) Representative images of immunoblotting for PPARy in HCASMCs versus HCAECs. C) densitometric analysis showing relative abundance of PPARy normalised to ATF2 protein as loading control.

\section{References}

1. Allender SS, P; Peto, V. European cardiovascular disease statistics. Brussels: European Heart Network, 2008.

2. Mendis S, et al. Global atlas on cardiovascular disease prevention and control. Geneva: World Health Organization in collaboration with the World Heart Federation and the World Stroke Organization, 2011: vi, 155 p.

3. Babapulle MN, et al. A hierarchical Bayesian meta-analysis of randomised clinical trials of drug-eluting stents. Lancet 2004;364:583-591.

4. Windecker S, et al. Sirolimus-eluting and paclitaxel-eluting stents for coronary revascularization. N Engl J Med 2005;353:653-662.

5. Urban P, De Benedetti E. Thrombosis: the last frontier of coronary stenting? Lancet 2007;369:619-621.

6. Daemen J, et al. Early and late coronary stent thrombosis of sirolimus-eluting and paclitaxel-eluting stents in routine clinical practice: data from a large two-institutional cohort study. Lancet 2007;369:667-678.

7. Shen ZJ, et al. Five-year clinical outcomes after coronary stenting of chronic total occlusion using sirolimus-eluting stents: Insights from the rapamycin-eluting stent evaluated at Rotterdam Cardiology Hospital-(Research) Registry. Catheterization and Cardiovascular Interventions 2009;74:979-986.

8. Layland J, et al. Extremely late drug-eluting stent thrombosis: 2037 days after deployment. Cardiovascular Revascularization Medicine 2009;10:55-57.

9. Al-Dehneh A, et al. Drug-eluting stent thrombosis 1,659 days after stent deployment: case report and literature review. Texas Heart Institute journal / from the Texas Heart Institute of St. Luke's Episcopal Hospital, Texas Children's Hospital 2010;37:343-346. 10. Garg S, Serruys PW. Coronary Stents: Looking Forward. Journal of the American College of Cardiology 2010;56:S43-S78.

11. Wilson JM. Unintended consequences: avoiding restenosis and stent thrombosis. Texas Heart Institute journal / from the Texas Heart Institute of St. Luke's Episcopal Hospital, Texas Children's Hospital 2010;37:341-342. 
12. Lüscher TF, et al. Drug-Eluting Stent and Coronary Thrombosis: Biological Mechanisms and Clinical Implications. Circulation 2007;115:1051-1058.

13. Stähli BE, et al. Drug-eluting stent thrombosis. Therapeutic Advances in Cardiovascular Disease 2009;3:45-52.

14. Litvin J, et al. Expression and function of periostin-like factor in vascular smooth muscle cells. American Journal of Physiology - Cell Physiology 2007;292:C1672-C1680.

15. Rzucidlo EM. Signaling pathways regulating vascular smooth muscle cell differentiation. Vascular 2009;17 Suppl 1:S15-20.

16. Dreyer $\mathrm{C}$, et al. Control of the peroxisomal beta-oxidation pathway by a novel family of nuclear hormone receptors. Cell 1992;68:879-887.

17. Bishop-Bailey D, et al. Intimal Smooth Muscle Cells as a Target for Peroxisome Proliferator-Activated Receptor- $\mathrm{CE} \geq$ Ligand Therapy. Circulation Research 2002;91:210-217. 18. Goetze S, et al. Peroxisome proliferator-activated receptor-gamma ligands inhibit nuclear but not cytosolic extracellular signal-regulated kinase/mitogen-activated protein kinase-regulated steps in vascular smooth muscle cell migration. Journal of cardiovascular pharmacology 2001;38:909-921.

19. Weber A-A, et al. Cyclooxygenase-independent inhibition of smooth muscle cell mitogenesis by ibuprofen. European Journal of Pharmacology 2000;389:67-69.

20. Brooks G, et al. Non-steroidal anti-inflammatory drugs (NSAIDs) inhibit vascular smooth muscle cell proliferation via differential effects on the cell cycle. Journal of Pharmacy and Pharmacology 2003;55:519-526.

21. Lehmann JM, et al. Peroxisome Proliferator-activated Receptors a and $\mathrm{Y}$ Are Activated by Indomethacin and Other Non-steroidal Anti-inflammatory Drugs. Journal of Biological Chemistry 1997;272:3406-3410.

22. Bernardo A, et al. Nuclear receptor peroxisome proliferator-activated receptor- $\gamma$ is activated in rat microglial cells by the anti-inflammatory drug HCT1026, a derivative of flurbiprofen. Journal of Neurochemistry 2005;92:895-903.

23. Heneka MT, et al. Acute treatment with the PPARy agonist pioglitazone and ibuprofen reduces glial inflammation and A $\beta 1-42$ levels in APPV717I transgenic mice. Brain 2005;128:1442-1453.

24. Rodriguez LG, et al. Wound-healing assay. Methods Mol Biol 2005;294:23-29.

25. Liang C-C, et al. In vitro scratch assay: a convenient and inexpensive method for analysis of cell migration in vitro. Nat. Protocols 2007;2:329-333.

26. Marx N, et al. Peroxisome Proliferator-Activated Receptor Gamma Activators Inhibit Gene Expression and Migration in Human Vascular Smooth Muscle Cells. Circulation Research 1998;83:1097-1103.

27. Reginato MJ, et al. Prostaglandins Promote and Block Adipogenesis through Opposing Effects on Peroxisome Proliferator-activated Receptor Y. Journal of Biological Chemistry 1998;273:1855-1858.

28. Leesnitzer LM, et al. Functional consequences of cysteine modification in the ligand binding sites of peroxisome proliferator activated receptors by GW9662. Biochemistry 2002;41:6640-6650.

29. Schmidt CE, et al. INTEGRIN CYTOSKELETAL INTERACTIONS IN MIGRATING FIBROBLASTS ARE DYNAMIC, ASYMMETRIC, AND REGULATED. Journal of Cell Biology 1993;123:977-991.

30. Markou T, et al. Glycogen synthase kinases 3alpha and 3beta in cardiac myocytes: regulation and consequences of their inhibition. Cell Signal 2008;20:206-218.

31. Giraldo A, et al. Feedback regulation by Atf3 in the endothelin-1-responsive transcriptome of cardiomyocytes: Egr1 is a principal Atf3 target. Biochem J 2012;444:343355. 
32. Bradford MM. A rapid and sensitive method for the quantitation of microgram quantities of protein utilizing the principle of protein-dye binding. Analytical biochemistry 1976;72:248-254.

33. Martin KA, et al. Rapamycin promotes vascular smooth muscle cell differentiation through insulin receptor substrate-1/phosphatidylinositol 3-kinase/Akt2 feedback signaling. $J$ Biol Chem 2007;282:36112-36120.

34. Han M, et al. Serum deprivation results in redifferentiation of human umbilical vascular smooth muscle cells. Am J Physiol Cell Physiol 2006;291:C50-58.

35. Cox LR, Ramos K. Allylamine-induced phenotypic modulation of aortic smooth muscle cells. J Exp Pathol (Oxford) 1990;71:11-18.

36. Thun MJ, et al. Nonsteroidal Anti-inflammatory Drugs as Anticancer Agents: Mechanistic, Pharmacologic, and Clinical Issues. Journal of the National Cancer Institute 2002;94:252-266.

37. Brinkman $\mathrm{HJ}$, et al. Involvement of cyclooxygenase- and lipoxygenase-mediated conversion of arachidonic acid in controlling human vascular smooth muscle cell proliferation. Thrombosis and haemostasis 1990;63:291-297.

38. Simons M. VEGF and Restenosis: The Rest of the Story. Arteriosclerosis, Thrombosis, and Vascular Biology 2009;29:439-440.

39. Silber $S$, et al. Unrestricted randomised use of two new generation drug-eluting coronary stents: 2-year patient-related versus stent-related outcomes from the RESOLUTE All Comers trial. The Lancet 2011;377:1241-1247.

40. Jaradat MS, et al. Activation of peroxisome proliferator-activated receptor isoforms and inhibition of prostaglandin $\mathrm{H} 2$ synthases by ibuprofen, naproxen, and indomethacin. Biochemical Pharmacology 2001;62:1587-1595.

41. Shimada T, et al. PPARgamma mediates NSAIDs-induced upregulation of TFF2 expression in gastric epithelial cells. FEBS Lett 2004;558:33-38.

42. Sastre $M$, et al. Nonsteroidal anti-inflammatory drugs repress $\beta$-secretase gene promoter activity by the activation of PPARY. Proceedings of the National Academy of Sciences of the United States of America 2006;103:443-448.

43. Hamblin M, et al. PPARs and the cardiovascular system. Antioxid Redox Signal 2009;11:1415-1452.

44. Munoz E, et al. Nonsteroidal anti-inflammatory drugs inhibit vascular smooth muscle cell proliferation by enabling the $\mathrm{Ca2+-dependent} \mathrm{inactivation} \mathrm{of} \mathrm{calcium} \mathrm{release-activated}$ calcium/orai channels normally prevented by mitochondria. J Biol Chem 2011;286:1618616196.

45. Sung JY, Choi HC. Aspirin-induced AMP-activated protein kinase activation regulates the proliferation of vascular smooth muscle cells from spontaneously hypertensive rats. Biochem Biophys Res Commun 2011;408:312-317.

46. Law RE, et al. Troglitazone inhibits vascular smooth muscle cell growth and intimal hyperplasia. J Clin Invest 1996;98:1897-1905.

47. Benson S, et al. Peroxisome proliferator-activated receptor (PPAR)-gamma expression in human vascular smooth muscle cells: inhibition of growth, migration, and c-fos expression by the peroxisome proliferator-activated receptor (PPAR)-gamma activator troglitazone. American journal of hypertension 2000;13:74-82.

48. Graf $\mathrm{K}$, et al. Troglitazone inhibits angiotensin II-induced DNA synthesis and migration in vascular smooth muscle cells. FEBS Lett 1997;400:119-121.

49. Goetze S, et al. PPAR gamma-ligands inhibit migration mediated by multiple chemoattractants in vascular smooth muscle cells. Journal of cardiovascular pharmacology 1999;33:798-806.

50. Wakino $\mathrm{S}$, et al. Peroxisome proliferator-activated receptor gamma ligands inhibit retinoblastoma phosphorylation and $\mathrm{G} 1-->S$ transition in vascular smooth muscle cells. $J$ Biol Chem 2000;275:22435-22441. 
51. Ogawa M, et al. A critical role of COX-2 in the progression of neointimal formation after wire injury in mice. Expert opinion on therapeutic targets 2009;13:505-511.

52. Schror K, Weber AA. Roles of vasodilatory prostaglandins in mitogenesis of vascular smooth muscle cells. Agents and actions. Supplements 1997;48:63-91.

53. Weber AA, et al. Antimitogenic effects of vasodilatory prostaglandins in coronary artery smooth muscle cells. Basic Res Cardiol 1998;93 Suppl 3:54-57.

54. Ferns GA, et al. Inhibition of neointimal smooth muscle accumulation after angioplasty by an antibody to PDGF. Science 1991;253:1129-1132.

55. Pukac L, et al. Platelet-Derived Growth Factor-BB, Insulin-like Growth Factor-I, and Phorbol Ester Activate Different Signaling Pathways for Stimulation of Vascular Smooth Muscle Cell Migration. Experimental Cell Research 1998;242:548-560.

56. Cospedal R, et al. Platelet-derived growth factor-BB (PDGF-BB) regulation of migration and focal adhesion kinase phosphorylation in rabbit aortic vascular smooth muscle cells: roles of phosphatidylinositol 3-kinase and mitogen-activated protein kinases.

Cardiovasc Res 1999;41:708-721.

57. Kliewer SA, et al. Differential expression and activation of a family of murine peroxisome proliferator-activated receptors. Proceedings of the National Academy of Sciences 1994;91:7355-7359.

58. Tontonoz $\mathrm{P}$, et al. Stimulation of adipogenesis in fibroblasts by PPAR ${ }^{32}$, a lipidactivated transcription factor. Cell 1994;79:1147-1156.

59. Law RE, et al. Expression and Function of PPARy in Rat and Human Vascular Smooth Muscle Cells. Circulation 2000;101:1311-1318.

60. Zahradka $\mathrm{P}$, et al. Peroxisome Proliferator-Activated Receptor $\mathrm{CE}_{ \pm}$and $\mathrm{CE} \geq$ Ligands Differentially Affect Smooth Muscle Cell Proliferation and Migration. Journal of

Pharmacology and Experimental Therapeutics 2006;317:651-659.

61. Parry TJ, et al. Drug-eluting stents: sirolimus and paclitaxel differentially affect cultured cells and injured arteries. Eur J Pharmacol 2005;524:19-29.

62. Chen YW, et al. Zotarolimus, a novel sirolimus analogue with potent anti-proliferative activity on coronary smooth muscle cells and reduced potential for systemic immunosuppression. Journal of cardiovascular pharmacology 2007;49:228-235. 
Figure 1.

A

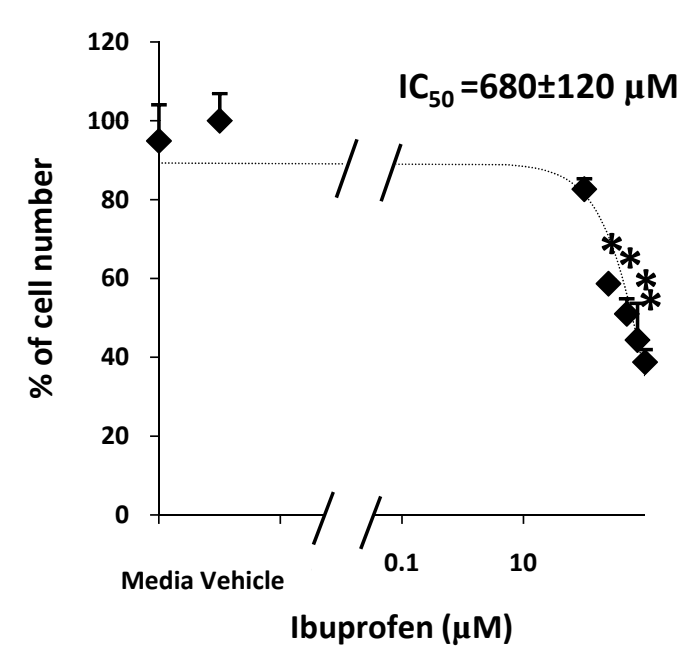

C

Control

\section{$500 \mu \mathrm{M}$}
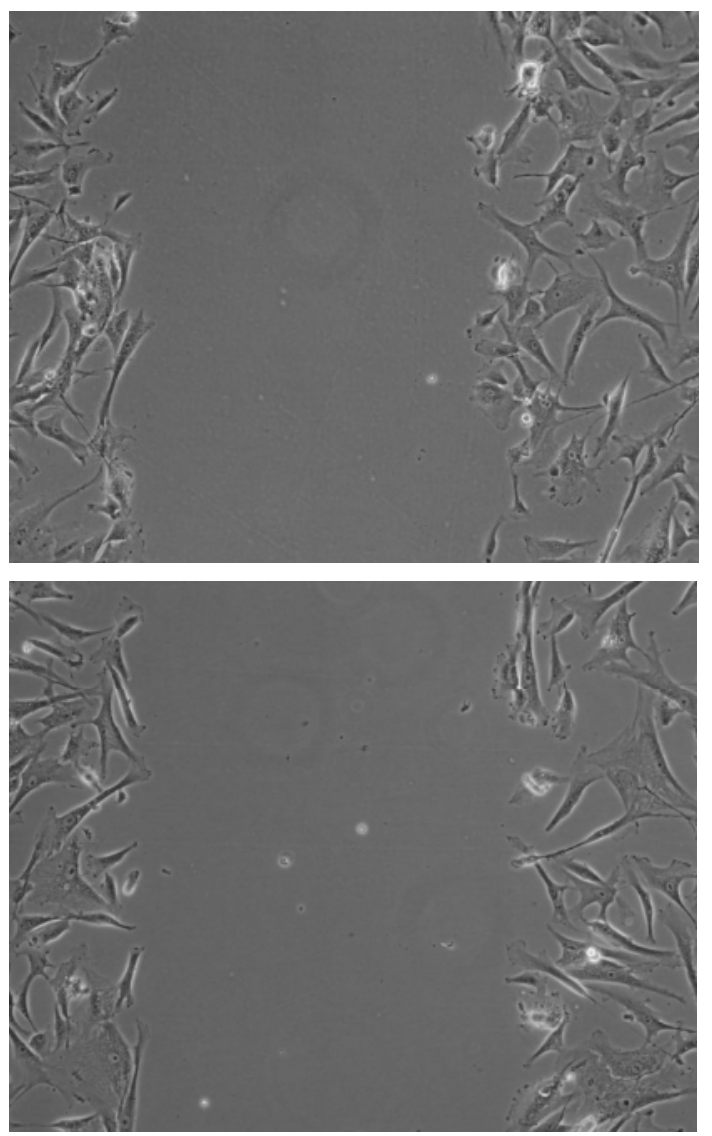

\section{$750 \mu \mathrm{M}$}

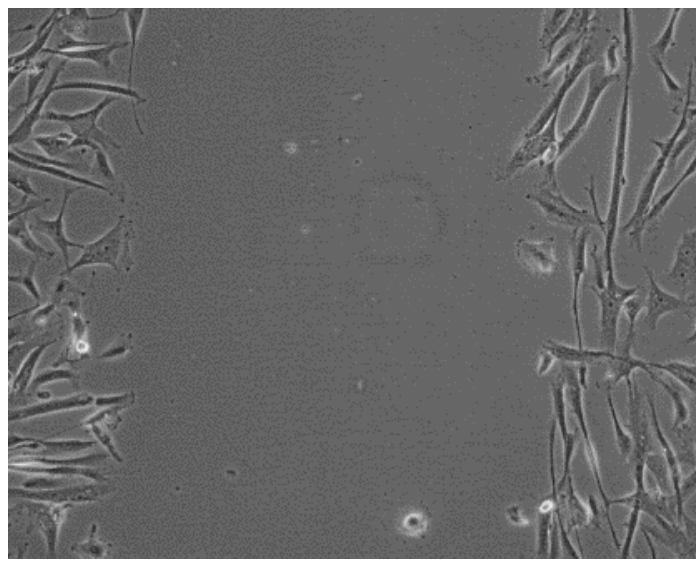

B

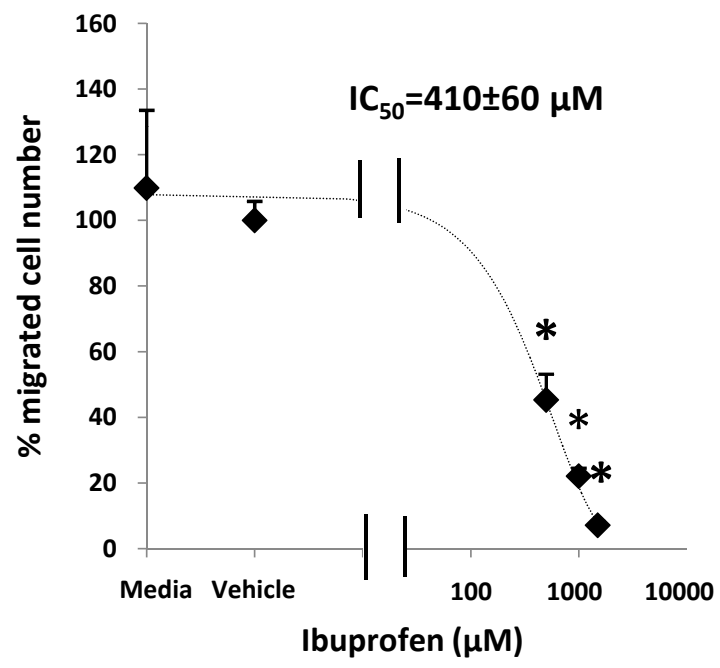

$24 \mathrm{~h}$
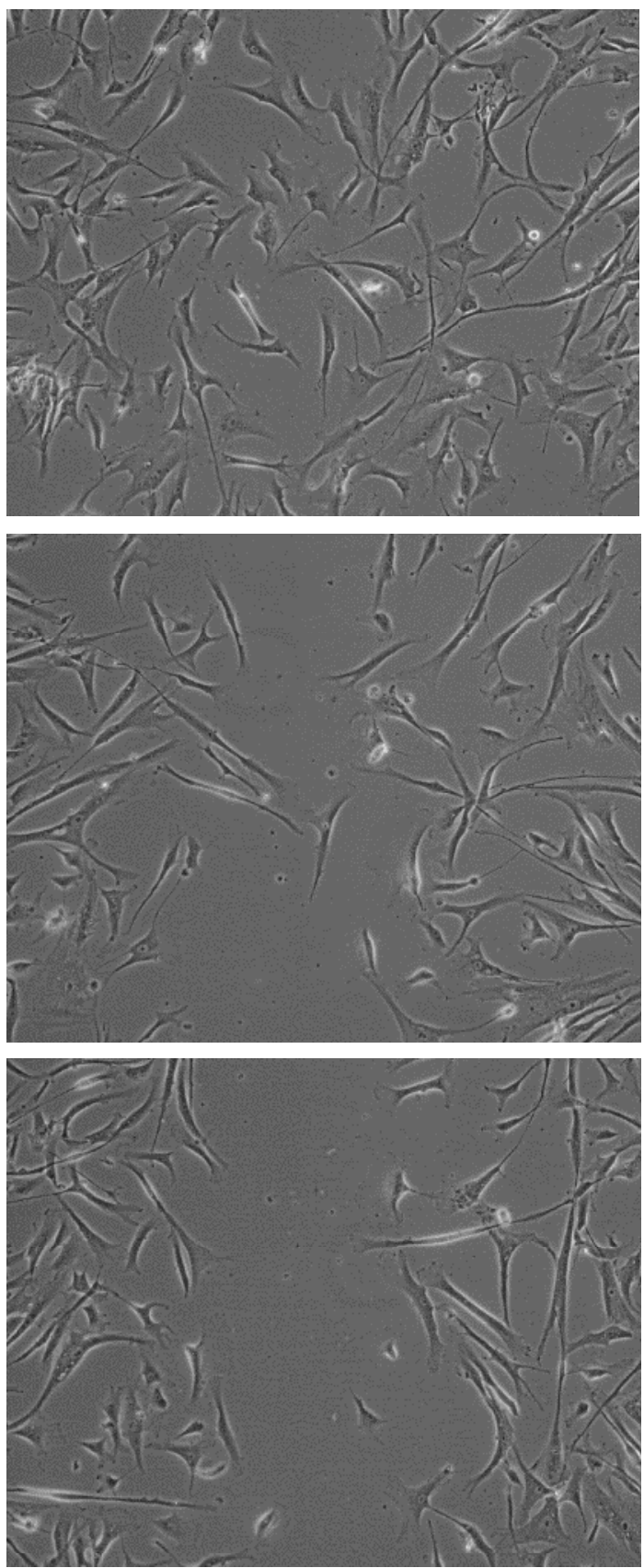
Figure 2.

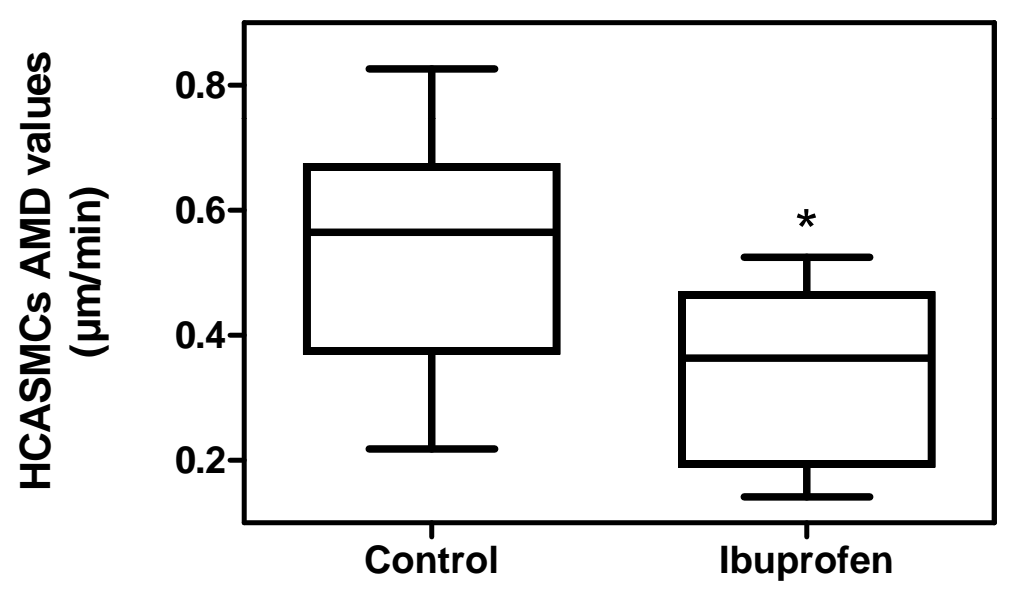


Figure 3.
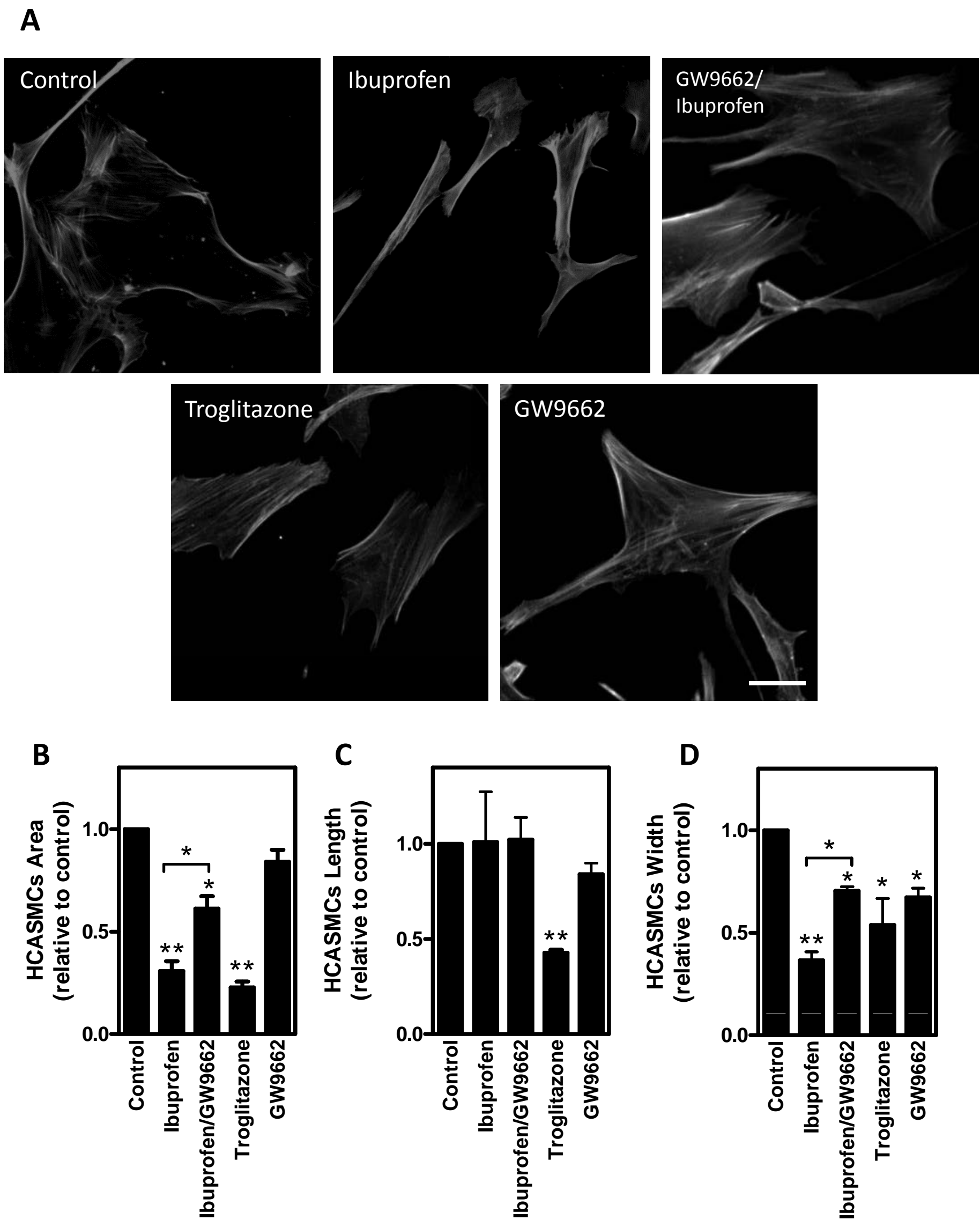
Figure 4.

A
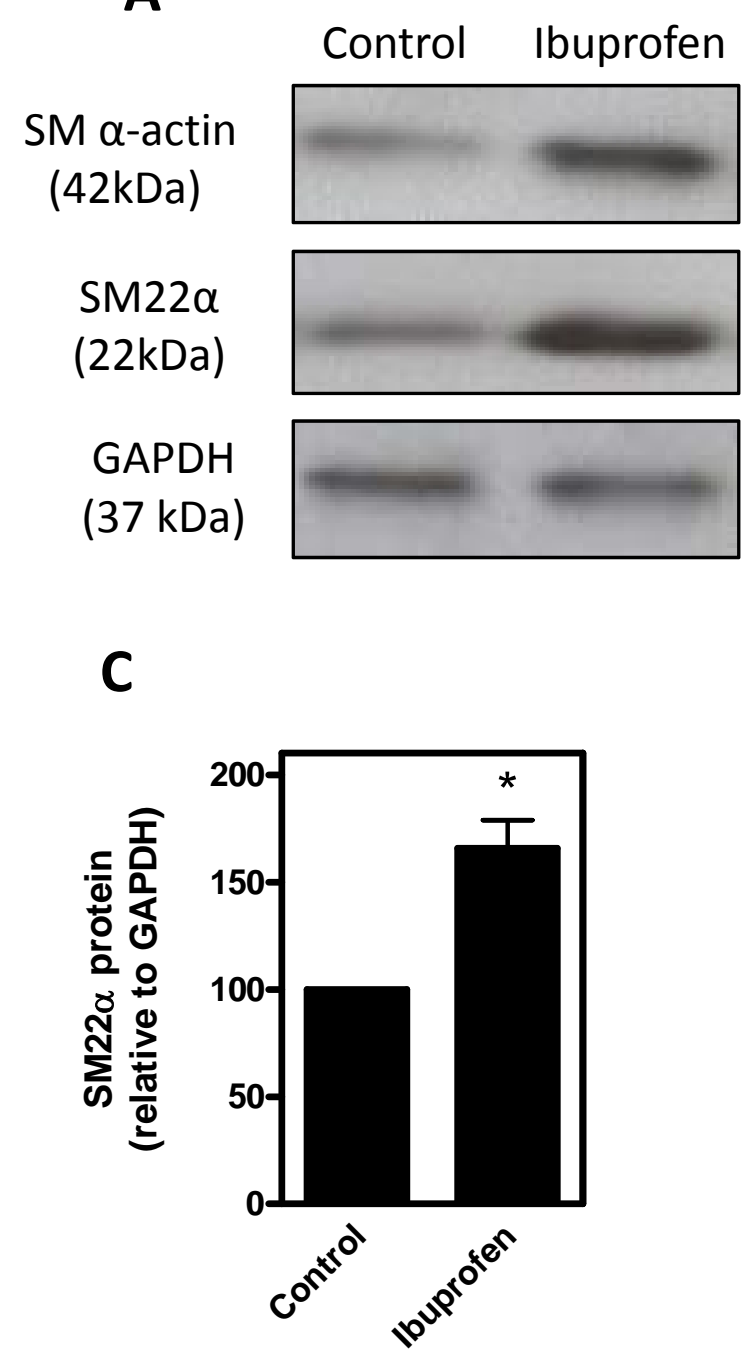

B
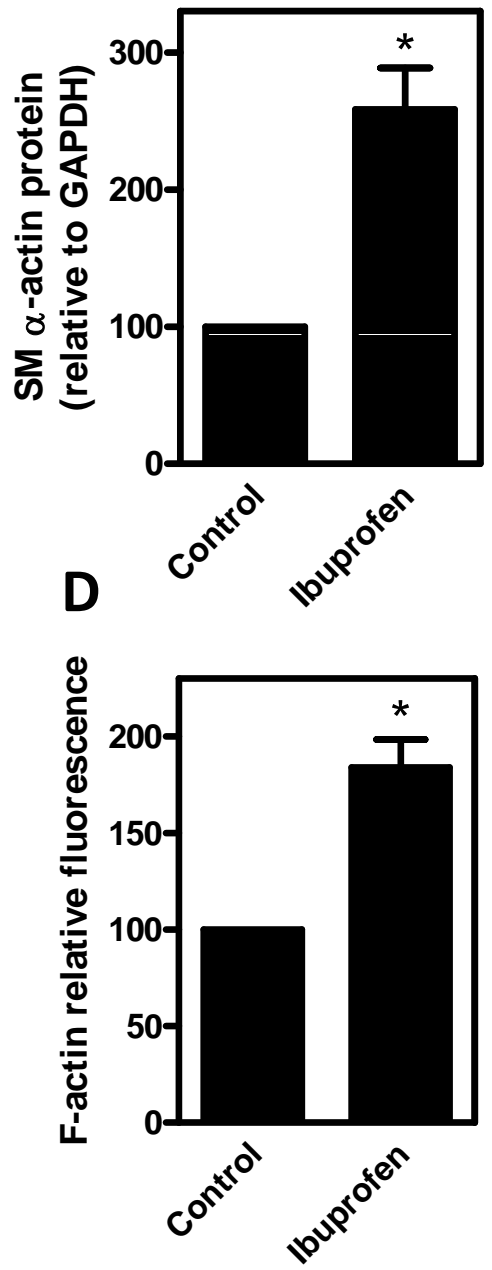
Figure 5.

A

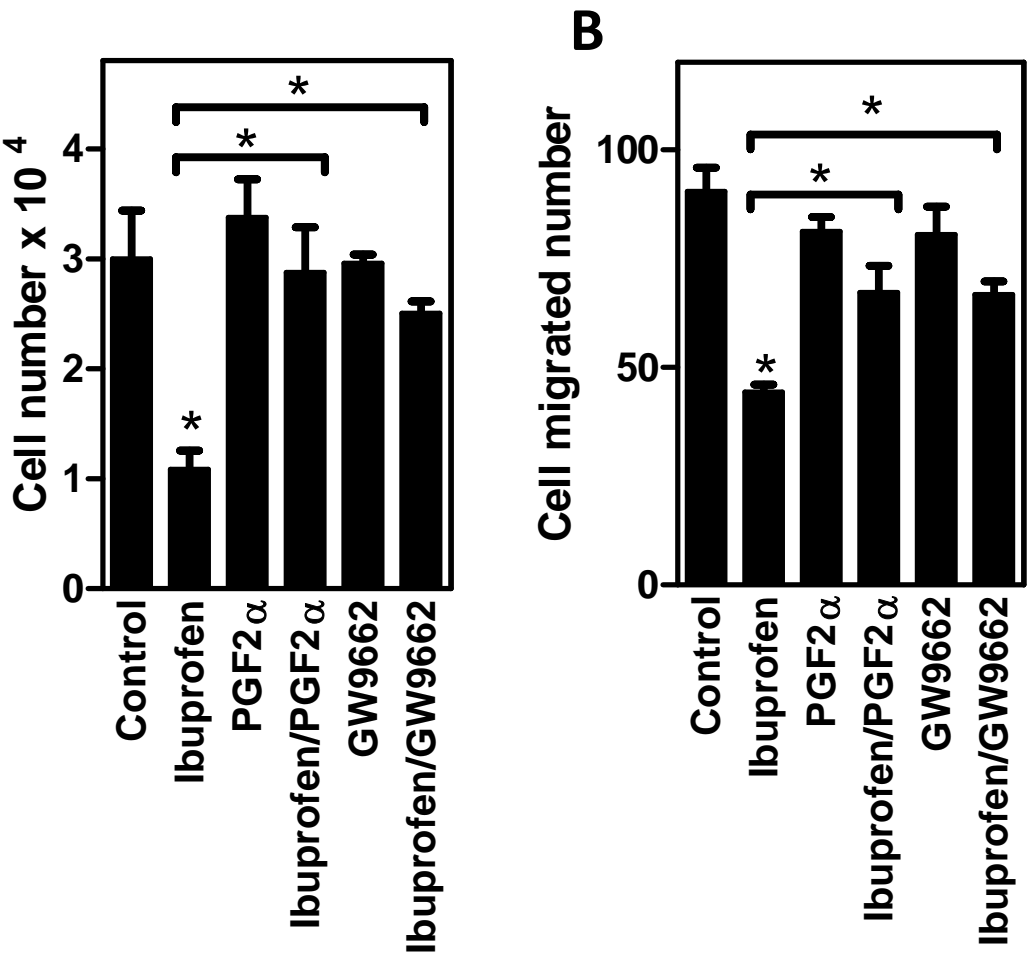

C

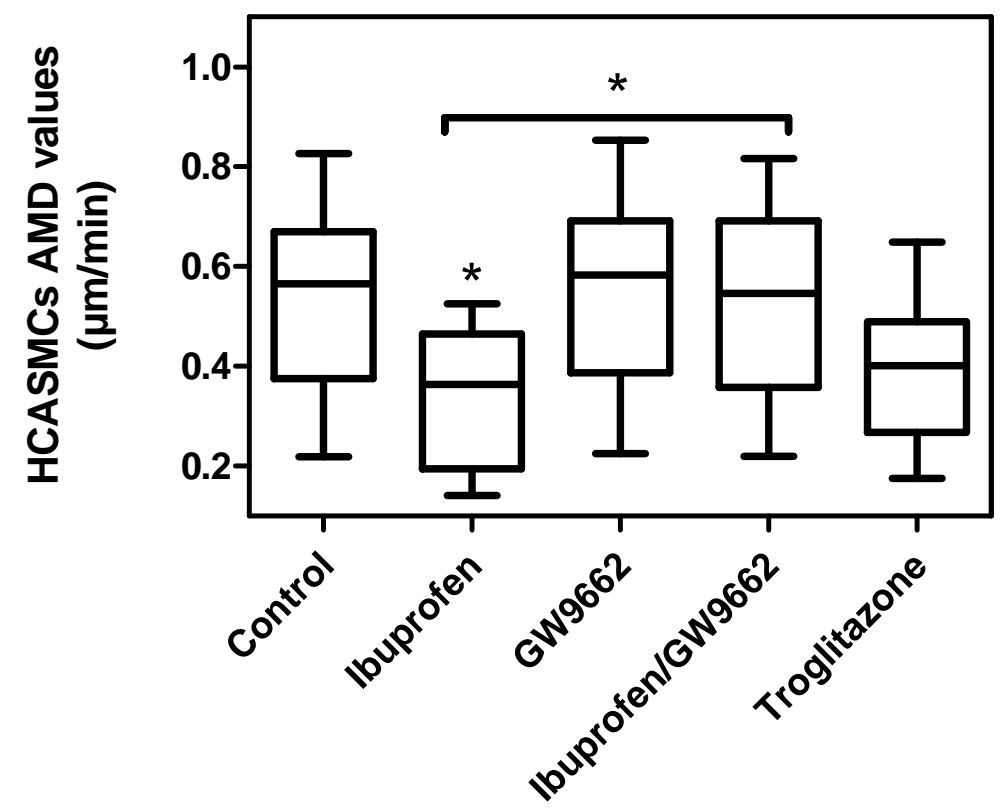


Figure 6.
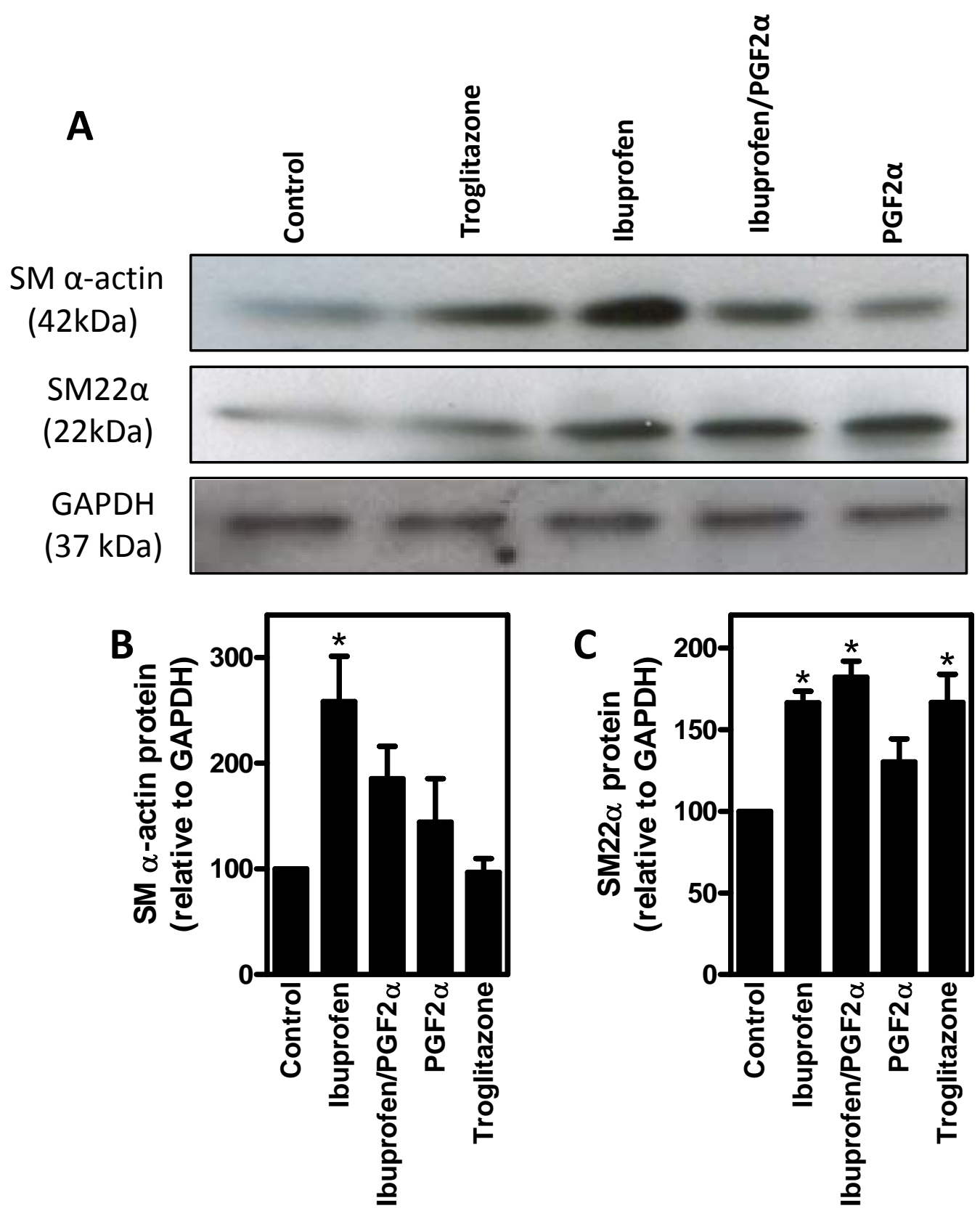
Figure 7.

A

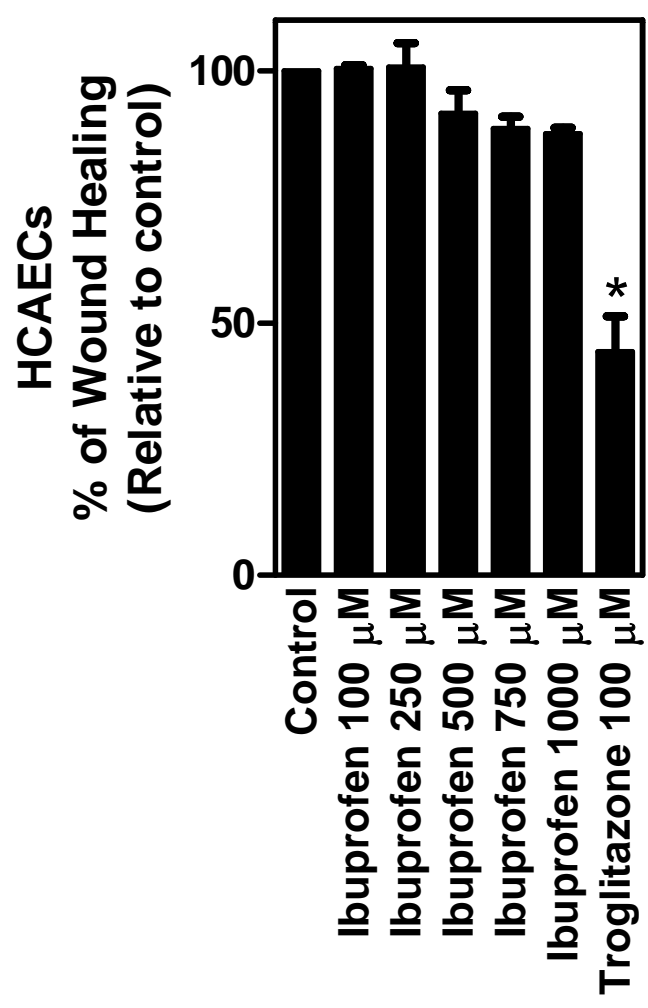

B

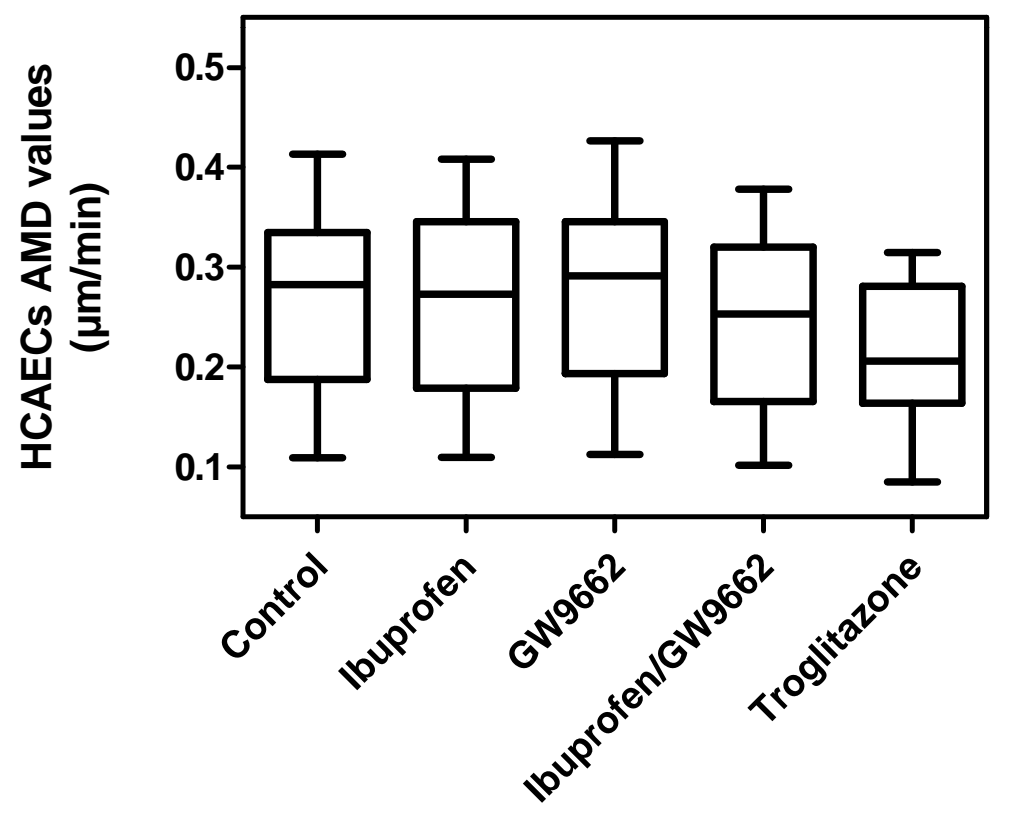

C

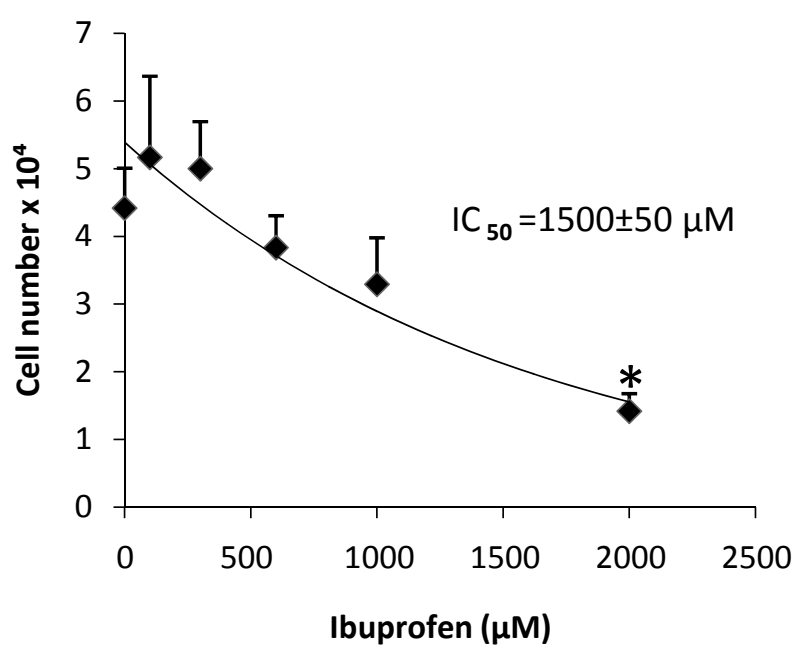


Figure 8.
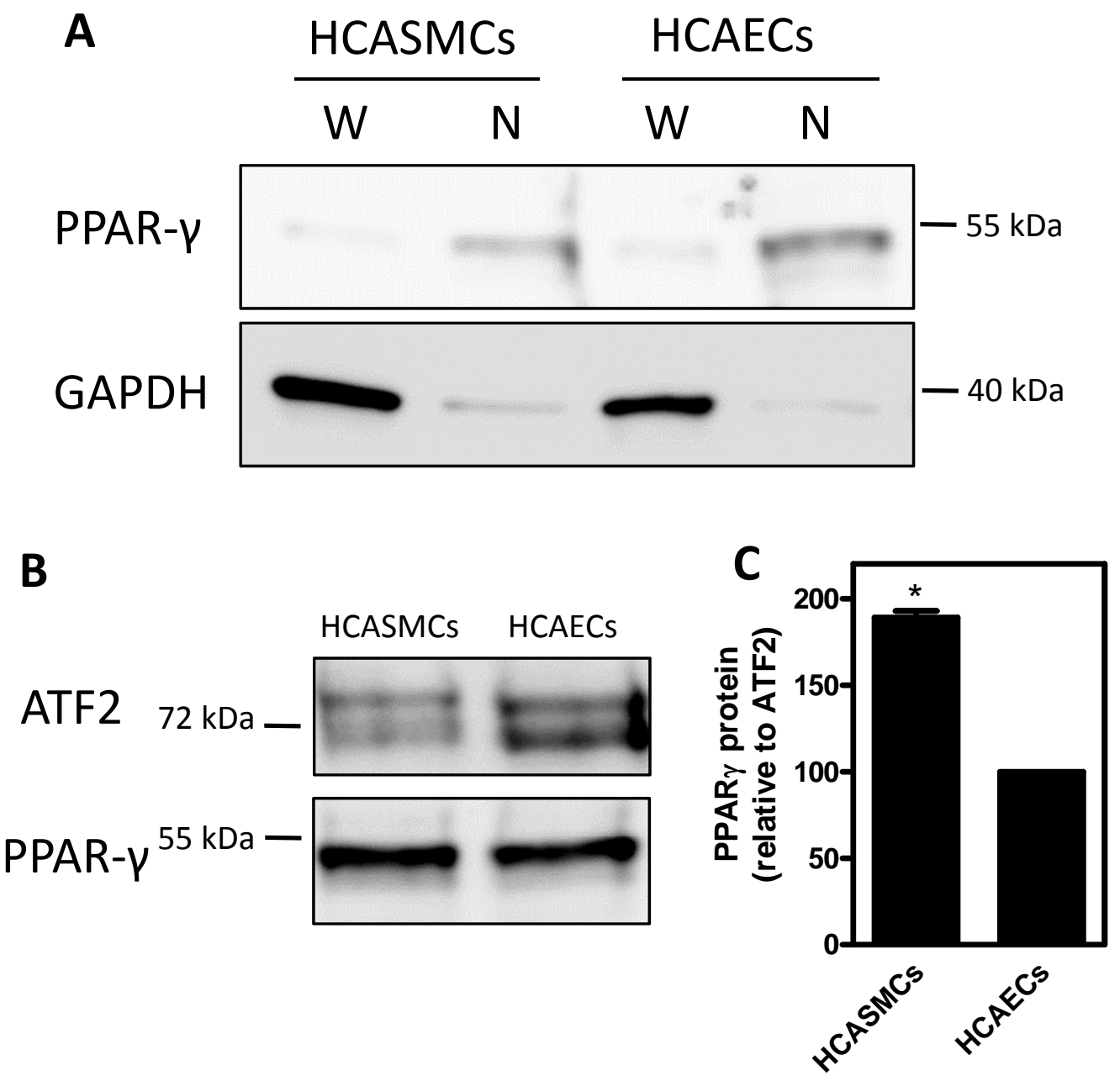